\title{
Body Mass Index as a Prognostic Factor for the Outcome of Traumatic Proximal Femoral Fractures Hossam AM Sallam ${ }^{1}$, Samir M Attia ${ }^{2}$, Ayman MM Ali Hussein ${ }^{3}$, Hisham KH Ismael*4 \\ Departments of ${ }^{1}$ Emergency Medicine, ${ }^{2}$ Vascular Surgery, ${ }^{3}$ Orthopedic Surgery and ${ }^{4}$ Critical Care Medicine, Faculty of Medicine, Mansoura University, Egypt \\ *Corresponding author: Hisham KH Ismael, Mobile: (+20) 01095603422, E-Mail: Heshamismae169@ gmail.com
}

\begin{abstract}
Background: Fractures of the proximal extremity of the femur are among the commonest traumatic injuries nowadays, not only because of their high incidence in the elderly population but also because of the accompanying morbidity and mortality. A well-documented report has suggested that body mass index (BMI) is a significant prognostic factor for hip fractures. Fractures of the proximal femur may be associated with low BMI, which is considered to be a risk factor.

Objective: To evaluate the effect of BMI on the outcome and complications of traumatic proximal femoral fractures in patients who were treated at Mansoura University Emergency Hospital.

Patient and method: This was prospective observational non-controlled clinical study was carried out on 134 patients with traumatic proximal femoral fractures selected from Mansoura University Emergency Hospital trauma patients from November 2018 to November 2019.

Results: This study demonstrated that the mean duration of hospital and ICU stay were $(11.18 \pm 8.23)$ and $(0.49 \pm 1.26)$ respectively. The percentage of overall morality was (7.5), (1.5) of which occurred in the first day while the remaining cases occurred in the first month (6\%). All demographic data and medical history were comparable among the studied cases except for height, weight and BMI indicating that BMI was the only different factors among cases. Incidence of postoperative complications was not affected by altered BMI. Duration of hospital and ICU admission wasn't affected by alteration in BMI but significantly affected the mortality in the first day.
\end{abstract}

Conclusion: The incidence of proximal femur fracture was higher in cases with higher BMI.

Keywords: BMI, Femoral Fracture, Outcome, Trauma.

\section{INTRODUCTION}

Fractures of the proximal extremity of the femur are among the commonest traumatic injuries nowadays, not only because of their high incidence in the elderly population but also because of the accompanying morbidity and mortality. It has been estimated that the incidence of hip fractures will increase dramatically over the next 20 years. This increase will be most evident among individuals over the age of 85 years ${ }^{(\mathbf{1})}$. Fractures of the proximal extremity of the femur involve those of the head, neck, trochanteric region and subtrochanteric region. All of them should be treated surgically, but there is no assent regarding the best surgical technique for each of them ${ }^{(2)}$.

Osteoporosis, sensory deficits caused by a stroke, dementia, muscular hypotrophy, decreased visual acuity, altered balance and reflexes, muscle weakness, neurological disorders, cardiovascular disorders, and osteomioarticular deformities are predisposing conditions to falls and, consequently, fractures. Regarding mortality due to hip fracture, other preoperative factors, identified at the patient's admission, are associated with an increase in study index, namely: being non-white, age, the presence of dementia, male gender, clinical comorbidities, and delirium ${ }^{(3)}$.
A well-documented report has suggested that body mass index (BMI) is a significant prognostic factor for hip fractures. In this context, fractures of the proximal femur may be associated with low BMI, which is considered to be a risk factor. Some authors have reported that the ideal BMI is $25-27.4 \mathrm{~kg} / \mathrm{m}^{2}$. Lower indices than this are considered to be important prognostic factors for mortality among young and old hospitalized patients ${ }^{(4)}$. It is suspected that obesity provides protection against fractures, but the mechanisms for such an association still remain poorly understood ${ }^{(5)}$. Varying results have been reported concerning the effect of body mass index (BMI) on polytrauma outcome ${ }^{(6)}$.

Although most studies focus on obesity with its associated preexisting medical diseases as a predictor for increased mortality rates, there is evidence that polytrauma patients with underweight also face an inferior outcome. $\mathrm{BMI}$ is an anthropometric index of weight-for-height and is defined as the weight in kilograms divided by the square of the height in meters $\left(\mathrm{kg} / \mathrm{m}^{2}\right){ }^{\text {(7)}}$. Despite some contradictory results, 3 population studies have demonstrated U-shaped curves relating BMI to mortality, suggesting increased mortality at both extremes of body weight ${ }^{(8)}$.

The aim of this study was to evaluate the effect of BMI on the outcome and complications of traumatic

This article is an open access article distributed under the terms and conditions of the Creative Commons ttribution (CC BY-SA) license (http://creativecommons.org/licenses/by/4.0/) 
proximal femoral fractures in patients who were treated at Mansoura University Emergency Hospital (MUEH).

\section{PATIENTS AND METHODS}

This prospective observational non-controlled clinical study was carried out on 134 patients with traumatic proximal femoral fractures selected from Mansoura University Emergency Hospital (MUEH) trauma patients from November 2018 to November 2019. We included patients with age group $\geq 50$ years old of both genders in our study. Patients with age group $<50$ years old, patients had pathological fractures, patients had primary bone tumours or bone metastasis, patients had distal femoral fractures or fractures of femoral diaphysis, patients using drugs causing bone mass loss (as in longterm bi-phosphonate use) and pregnant females were excluded from our study.

All patients were subjected to resuscitation, history taking, physical examination and laboratory investigations as well as radiological investigations as Xray pelvis anteroposterior (AP) view, X-ray hip with femur AP and lateral views and focused assessment with sonography for trauma (FAST). Five BMI categories were created: low weight $\left(<18.5 \mathrm{~kg} / \mathrm{m}^{2}\right)$; normal weight $(18.5-$ $\left.25 \mathrm{~kg} / \mathrm{m}^{2}\right)$; overweight $\left(25-30 \mathrm{~kg} / \mathrm{m}^{2}\right)$; obese (30-40 $\mathrm{kg} / \mathrm{m}^{2}$ ) and morbid obese (more than $40 \mathrm{~kg} / \mathrm{m}^{2}$ ) according to WHO categories. Outcome was estimated by hospital mortality, death within 24 hours, death within one month, multiple organ failure, sepsis, presence of mal-union, nonunion, ICU stay and hospital stay.

\section{Ethical consideration:}

The study was approved by Institutional Review Board (IRB), Faculty of Medicine, Mansoura University. Informed written consent was obtained from each participant sharing in the study. Confidentiality and personal privacy were respected in all levels of the study. Collected data were not used for any other purpose.

\section{Statistical Analysis}

The collected data were revised, coded, processed and analyzed using SPSS program (Statistical Package for the Social Sciences) for windows version 20 (SPSS Inc., Chicago, IL, USA). The data were presented as number and percentages for the qualitative data, mean, standard deviations, ranges, and median with interquartile range (IQR) for the quantitative data. The appropriate tests of significance were conducted. Chi-square test was used in the comparison between the two groups with qualitative data and Fisher exact test was used instead of the Chisquare test when the expected count in any cell was less than 5. Independent t-test was used in the comparison between the two groups with quantitative data. $\mathrm{P}$ value < 0.05 was considered significant.

\section{RESULTS}

The demographic characteristics and medical history of the studied patients are shown in table (1).

Table (1): Demographic characteristics and medical history of the studied patients:

\begin{tabular}{|c|c|c|c|c|c|c|c|}
\hline \multirow{2}{*}{\multicolumn{2}{|c|}{ (1) }} & \multicolumn{6}{|c|}{ All patients $(n=134)$} \\
\hline & & \multicolumn{2}{|l|}{ Mean \pm SD } & Median & Minimum & Maximum & IQR \\
\hline \multicolumn{2}{|l|}{ Age } & \multicolumn{2}{|l|}{$69.72 \pm 9.88$} & 69.00 & 50.00 & 96.00 & $63.00,75.25$ \\
\hline \multicolumn{2}{|l|}{ Weight } & \multicolumn{2}{|l|}{$86.67 \pm 22.46$} & 84.10 & 41.40 & 158.40 & $69.72,99.63$ \\
\hline \multicolumn{2}{|l|}{ Height } & \multicolumn{2}{|c|}{$170.79 \pm 11.43$} & 171.85 & 144.00 & 198.00 & $163.23,177.85$ \\
\hline \multicolumn{2}{|l|}{ BMI } & $30.27 \pm 9.62$ & & 28.22 & 16.99 & 60.10 & $23.22,36.03$ \\
\hline \multirow{2}{*}{ Gender } & \multicolumn{2}{|c|}{ Male } & \multicolumn{5}{|c|}{$56.7 \%(76)$} \\
\hline & \multicolumn{2}{|c|}{ Female } & \multicolumn{5}{|c|}{$43.3 \%(58)$} \\
\hline \multirow{5}{*}{$\begin{array}{l}\text { BMI } \\
\text { Class }\end{array}$} & Un & erweight & \multicolumn{5}{|c|}{$14.2 \%(19)$} \\
\hline & \multicolumn{2}{|c|}{ Normal } & \multicolumn{5}{|c|}{$20.9 \%(28)$} \\
\hline & \multicolumn{2}{|c|}{ Overweight } & \multicolumn{5}{|c|}{$16.4 \%(22)$} \\
\hline & \multicolumn{2}{|c|}{ Obese } & \multicolumn{5}{|c|}{$32.1 \%(43)$} \\
\hline & \multirow{2}{*}{\multicolumn{2}{|c|}{ Morbid Obesity }} & \multicolumn{5}{|c|}{$16.4 \%(22)$} \\
\hline DM & & & \multicolumn{5}{|c|}{$60.4 \%(81)$} \\
\hline \multicolumn{3}{|l|}{ HTN } & \multicolumn{5}{|c|}{$67.2 \%(90)$} \\
\hline \multicolumn{3}{|l|}{ IHD } & \multicolumn{5}{|c|}{$35.8 \%(48)$} \\
\hline
\end{tabular}

Comparison of demographic characteristics and medical history according to BMI is shown in table (2). There was a statistically significant difference between underweight, normal weight, overweight, obese and morbid obese patients as regards age, weight and BMI. 
Table (2): Comparison of demographic characteristics and medical history according to BMI

\begin{tabular}{|c|c|c|c|c|c|c|c|}
\hline & & $\begin{array}{l}\text { Underweight } \\
\quad(n=19)\end{array}$ & $\begin{array}{c}\text { Normal } \\
(n=28)\end{array}$ & $\begin{array}{l}\text { Overweight } \\
(n=22)\end{array}$ & Obese $(n=43)$ & $\begin{array}{c}\text { Morbid } \\
\text { Obesity }(n=22)\end{array}$ & $\mathbf{p}$ \\
\hline \multicolumn{2}{|l|}{ Age } & $66.26 \pm 8.77$ & $70.18 \pm 10.37$ & $67.86 \pm 8.35$ & $70.98 \pm 10.05$ & $71.50 \pm 10.98$ & 0.337 \\
\hline \multicolumn{2}{|l|}{ Weight } & $59.53 \pm 8.21$ & $70.05 \pm 8.89$ & $80.93 \pm 8.28$ & $95.63 \pm 11.50$ & $119.51 \pm 18.42$ & $<0.001$ \\
\hline \multicolumn{2}{|l|}{ Height } & $179.56 \pm 14.01$ & $173.78 \pm 9.16$ & $174.03 \pm 9.28$ & $168.87 \pm 8.25$ & $159.93 \pm 10.24$ & $<0.001$ \\
\hline \multicolumn{2}{|l|}{ BMI } & $18.43 \pm 1.07$ & $23.12 \pm 1.45$ & $26.69 \pm 1.21$ & $33.53 \pm 3.29$ & $46.79 \pm 6.55$ & $<0.001$ \\
\hline \multirow{2}{*}{ Gender } & Male & $47.4 \%(9)$ & $67.9 \%(19)$ & $77.3 \%(17)$ & $55.8 \%(24)$ & $31.8 \%(7)$ & \multirow{2}{*}{0.022} \\
\hline & Female & $52.6 \%(10)$ & $32.1 \%(9)$ & $22.7 \%(5)$ & $44.2 \%(19)$ & $68.2 \%(15)$ & \\
\hline \multicolumn{2}{|l|}{ DM } & $78.9 \%(15)$ & $50.0 \%$ & $54.5 \%(12)$ & $53.5 \%(23)$ & $77.3 \%(17)$ & 0.099 \\
\hline \multicolumn{2}{|l|}{ HTN } & $47.4 \%(9)$ & $60.7 \%(17)$ & $68.2 \%(15)$ & $74.4 \%(32)$ & $77.3 \%(17)$ & 0.202 \\
\hline \multicolumn{2}{|l|}{ IHD } & $21.1 \%(4)$ & $25.0 \%(7)$ & $50.0 \%$ & $39.5 \%(17)$ & $40.9 \%$ (9) & 0.226 \\
\hline
\end{tabular}

Site and type of fractures were seen in table (3).

Table (3): Side, type of the fracture, other associated injuries and surgical decision in the studied patients

\begin{tabular}{|l|l|c|}
\hline \multirow{2}{*}{ Side } & Right & All patients (n= 134) \\
\cline { 2 - 3 } & Left & $49.3 \%(66)$ \\
\hline \multirow{2}{*}{ Type } & NOF & $50.7 \%(68)$ \\
\cline { 2 - 3 } & Intertrochanteric & $91 \%(122)$ \\
\hline \multirow{2}{*}{ Surgical Decision } & Conserve & $9 \%(12)$ \\
\cline { 2 - 3 } & Surgery & $14.9 \%(20)$ \\
\hline
\end{tabular}

Table 4 shows a statistically significant difference between underweight, normal, overweight, obese and morbid obese patients as regards type of the fracture.

Table (4): Side, type of the fracture, other associated injuries and surgical decision according to BMI:

\begin{tabular}{|c|c|c|c|c|c|c|c|}
\hline & & $\begin{array}{l}\text { Underweight } \\
\qquad(n=19)\end{array}$ & $\begin{array}{c}\text { Normal } \\
(n=28)\end{array}$ & $\begin{array}{l}\text { Overweight } \\
\quad(n=22)\end{array}$ & bese $(n=43)$ & $\begin{array}{l}\text { Morbid } \\
\text { Obesity } \\
(n=22)\end{array}$ & $\mathbf{P}$ \\
\hline \multirow{2}{*}{ Side } & Right & $42.1 \%(8)$ & $46.4 \%(13)$ & $36.4 \%(8)$ & $65.1 \%(28)$ & $40.9 \%(9)$ & \multirow{2}{*}{0.142} \\
\hline & Left & $57.9 \%(11)$ & $53.6 \%(15)$ & $63.6 \%(14)$ & $34.9 \%(15)$ & $59.1 \%(13)$ & \\
\hline \multirow{2}{*}{ Type } & NOF & $73.7 \%(14)$ & $85.7 \%(24)$ & $100.0 \%(22)$ & $95.3 \%(41)$ & $95.5 \%(21)$ & \multirow{2}{*}{0.020} \\
\hline & Intertrochanteric & $26.3 \%(5)$ & $14.3 \%(4)$ & $0.0 \%(0)$ & $4.7 \%(2)$ & $4.5 \%(1)$ & \\
\hline \multirow{2}{*}{$\begin{array}{l}\text { Surgical } \\
\text { Decision }\end{array}$} & Conserve & $5.3 \%(1)$ & $17.9 \%(5)$ & $0.0 \%(0)$ & $18.6 \%(8)$ & $27.3 \%(6)$ & \multirow{2}{*}{0.070} \\
\hline & Surgery & $94.7 \%(18)$ & $82.1 \%(23)$ & $100.0 \%(22)$ & $81.4 \%(35)$ & $72.7 \%(16)$ & \\
\hline
\end{tabular}

Table 5 shows that there was no statistically significant difference existed between underweight, normal weight, overweight, obese and morbid obese patients as regards the mode of trauma.

Table (5): Mode of trauma, mental status and FAST on admission according to BMI

\begin{tabular}{|c|c|c|c|c|c|c|c|}
\hline & & $\begin{array}{l}\text { Underweight } \\
\qquad(n=19)\end{array}$ & ormal $(n=28)$ & $\begin{array}{l}\text { Overweight } \\
\quad(n=22)\end{array}$ & $\begin{array}{c}\text { Obese } \\
(n=43)\end{array}$ & $\begin{array}{l}\text { Morbid } \\
\text { Obesity } \\
(n=22)\end{array}$ & $\mathbf{P}$ \\
\hline \multirow{3}{*}{ Trauma } & FDS & $10.5 \%(2)$ & $14.3 \%(4)$ & $4.5 \%(1)$ & $20.9 \%(9)$ & $18.2 \%(4)$ & \multirow{3}{*}{0.561} \\
\hline & FTG & $84.2 \%(16)$ & $75.0 \%(21)$ & $95.5 \%(21)$ & $69.8 \%(30)$ & $72.7 \%(16)$ & \\
\hline & RTA & $5.3 \%(1)$ & $10.7 \%(3)$ & $0.0 \%(0)$ & $9.3 \%(4)$ & $9.1 \%(2)$ & \\
\hline
\end{tabular}


Table (6) shows the postoperative complications in the studied patients.

Table (6): Postoperative complication in the studied patients

\begin{tabular}{|l|c|}
\hline & All patients (n= 134) \\
\hline Sepsis & $3 \%(4)$ \\
\hline MOF & $1.5 \%(2)$ \\
\hline Malunion & $3 \%(4)$ \\
\hline
\end{tabular}

Hospital and ICU stay and patient mortality of the studied patients are shown in table (7).

Table (7): Hospital and ICU stay and patient mortality of the studied patients

All patients $(n=134)$

\begin{tabular}{|l|c|c|c|c|c|}
\hline & Mean and SD & Median & Minimum & Maximum & IQR \\
\hline Hospital stay & $11.18 \pm 8.23$ & 9.00 & 1.00 & 41.00 & $6.00,14.25$ \\
\hline ICU stay & $0.49 \pm 1.26$ & 0.00 & 0.00 & 5.00 & $0.00,0.00$ \\
\hline Overall mortality & \multicolumn{5}{|c|}{$7.5 \%(10)$} \\
\hline First day mortality & \multicolumn{5}{|c|}{$6 \%(8)$} \\
\hline First month mortality & \multicolumn{5}{|c|}{} \\
\hline
\end{tabular}

Table 8 shows a statistically significant difference between underweight, normal, overweight, obese and morbid obese patients as regards first day mortality.

Table (8): Correlation between both hospital and ICU stay and patient mortality of the studied patients

\begin{tabular}{|l|l|l|c|c|c|c|}
\hline & $\begin{array}{c}\text { Underweight } \\
(\mathbf{n = 1 9})\end{array}$ & $\begin{array}{c}\text { Normal } \\
(\mathbf{n = ~ 2 8})\end{array}$ & $\begin{array}{c}\text { Overweight } \\
(\mathbf{n = 2 2})\end{array}$ & $\begin{array}{c}\text { Obese } \\
(\mathbf{n = 4 3})\end{array}$ & $\begin{array}{c}\text { Morbid Obesity } \\
(\mathbf{n = 2 2})\end{array}$ & $\mathbf{P}$ \\
\hline Hospital stay & $12.16 \pm 8.36$ & $10.86 \pm 5.21$ & $9.32 \pm 4.32$ & $11.47 \pm 8.85$ & $12.05 \pm 12.39$ & 0.790 \\
\hline ICU stay & $0.63 \pm 1.300$ & $0.21 \pm 0.833$ & $0.18 \pm 0.853$ & $0.53 \pm 1.369$ & $0.95 \pm 1.647$ & 0.200 \\
\hline $\begin{array}{l}\text { Overall } \\
\text { mortality }\end{array}$ & $0.0 \%(0)$ & $3.6 \%(1)$ & $4.5 \%(1)$ & $9.3 \%(4)$ & $18.2 \%(4)$ & 0.179 \\
\hline $\begin{array}{l}\text { First day } \\
\text { mortality }\end{array}$ & $0.0 \%(0)$ & $0.0 \%(0)$ & $0.0 \%(0)$ & $0.0 \%(0)$ & $9.1 \%(2)^{*}$ & $\mathbf{0 . 0 3 5}$ \\
\hline $\begin{array}{l}\text { First month } \\
\text { mortality }\end{array}$ & $0.0 \%(0)$ & $3.6 \%(1)$ & $4.5 \%(1)$ & $9.3 \%(4)$ & $9.1 \%(2)$ & 0.636 \\
\hline
\end{tabular}

\section{DISCUSSION}

The most frequent mood of trauma in the current study was fall to ground (FTG) followed falling downstairs (FDS) and lastly road traffic accident (RTA). In addition, there were no statistically significant difference between BMI and both mood of trauma and mental status.

The current study revealed that the highest incidence of proximal fractures of the femur was in overweight, obese and morbid obesity groups, while lower incidences were present in underweight and normal weight groups. Therefore, the present study revealed that BMI was correlated positively with proximal fractures of the femur. In accordance, Nielson $\boldsymbol{e t}$ al. ${ }^{(9)}$ performed a large prospective study of older men who were normal weight or heavier, most hip (62\%) and non-spine fractures (68\%) occurred in overweight or obese men, who represented $72 \%$ of the cohort. In addition, they revealed that obesity was associated with an increased risk of hip and other fractures after adjustment for bone mineral density (BMD), but this association appeared to be due at least in part to confounding by deficits in physical performance. In addition, some previous analyses have noted a tendency for increased weight to be associated with higher fracture risk ${ }^{(10-13)}$.

While Fini et al. ${ }^{(14)}$ revealed that overweight and obesity protect bone, thus reducing the fracture risk and the development of osteoporosis in older adults. On the other hand, a case-control study performed by Pagani $\boldsymbol{e t}$ al. (4) revealed that, among the patients with proximal fractures of the femur, 5.6\% presented low weight, $43.8 \%$ normal weight, $33.7 \%$ overweight, and $9.8 \%$ obesity. Also, a study conducted by Alfaro-Acha et al. (1) confirmed that there was an inverse relationship between body weight and the risk of fracturing of the proximal 
extremity of the femur and reported that a $10 \%$ weight loss significantly increased the risk of hip fractures among individuals aged 65 years and over.

To explain the discrepancies among the current study and the other preceding studies, we must know these facts at first. Type of obesity plays an important role in the risk of hip fracture and stability of intertrochanteric fracture due to its impact on peri-trochanteric fat. Two predominant types of obesity have been described. Android obesity, which is more common in men, consists of primarily abdominal and thoracic distributions of adipose tissue. The second type is gynecoid type obesity where adipose tissue is found primarily in the hip and thigh region. While obesity in general is protective against hip fracture, android obesity confers an increased risk of fracture independently of BMD ${ }^{(15,16)}$.

The current study revealed that, fracture neck of the femur was the most common type of fracture followed by intertrochanteric fracture. In addition, the percentage of right to left fracture was comparable to some extent among the studied patients. While, Cunha and Veado (17) analyzed 190 patients (142 women and 48 men; mean age of 79 years) in the state of Minas Gerais, Brazil who were hospitalized with fractures in the proximal extremity of the femur in the orthopedic ward, among whom the incidence of trochanteric fractures was $50 \%$, femoral neck fractures $44 \%$ and subtrochanteric fractures $6 \%$. In contrary, Pagani et al. ${ }^{(4)}$ revealed that the main types of fracture presented in their study were trochanteric fractures, with 47 cases $(62.2 \%)$, followed by femoral neck fractures 27 cases $(36 \%)$ then subtrochanteric fractures, with one case only $(1.8 \%)$.

As regards the duration of hospital and ICU stay, the present study revealed that the mean duration differs among the all five groups but this differences were not statistically significant. Although, Siegmeth et al. (18), revealed that length of hospital stay following proximal femur fracture mainly depends on the effect of prolonged delay before operation, Smektala et al. ${ }^{(19)}$ revealed that such delay before operation may induce more complication but not increase the length of hospital stay. Similarly, Edelmuth et al. ${ }^{(20)}$ revealed that the duration of hospital stay in the majority of cases $(43.3 \%)$ was between (7-15 day). In other words, the mean duration of the majority of cases was $11 \pm 4$, which was comparable to the current study. While, Tan et al. ${ }^{(21)}$ revealed that there were higher duration of the mean length of hospital stay for the surgical hip fracture patients (15.7 days) in relation to the current study. In contrary, Hoffmann et al. ${ }^{(22)}$ revealed in their study that there was gradual increase in duration of hospital stay as regards BMI. The mean duration of hospital stay were $23,26,28$, and 32 for underweight, normal, overweight and obese respectively with highly statistically significant differences $(\mathrm{P}<0.001)$, however they revealed that there were no statistically significant difference in the duration of ICU admission among all studied groups (underweight, normal, overweight and obese) $(\mathrm{P}=0.089)$, which was in agreement with the present study.

The current study revealed that the overall mortality was $7.5 \%$ of which $1.5 \%$ occurred in the first day and $6 \%$ occurred in the first month. In addition, the majority of dead cases had morbid obesity with highly statistically significant difference in mortality rates among morbid obesity cases and all other groups in the first day mortality. In accordance, Choban et al. ${ }^{(23)}$ performed the first study that evaluated the relationship between BMI and trauma, which included 184 multiple traumatized patients. The authors showed a $42 \%$ mortality rate in obese patients compared to $5 \%$ in those with normal weight. Moreover, Edelmuth et al. (20) revealed that patients with hip fractures generally present comorbidities and are susceptible to clinical complications, and have an $11.9 \%$ mortality rate. In contrary, Hoffmann et al. ${ }^{(22)}$ revealed that increase in mortality with higher BMI, but these differences were not significant $(p=0.76)$. In addition, the duration of in-hospital treatment, length of ICU stay, and duration of mechanical ventilation consistently increased with higher BMI. Moreover, Andruszkow et al. (24) revealed that obesity is considered as a major risk factor for development of Multiple Organ Dysfunction Syndrome (MODS) in severely traumatized patients without affection the mortality rates. In addition, underweight patients revealed twice the mortality rate in comparison with obese cases, which may be of clinical significance and should be considered in future diagnostic and therapeutic steps.

\section{CONCLUSION}

In conclusion, the incidence of proximal femur fracture was higher in cases with higher BMI. Postoperative complications (sepsis, MOF and malunion) and duration of hospital and ICU admission were not affected by the alteration in BMI, while the overall mortality in the first day significantly affected specifically in morbid obese group. In addition, obesity represents a global health burden with a higher incidence of mortality and ICU admission especially in morbid obesity cases.

\section{REFERENCES}

1. Alfaro- Acha A, Ostir G, Markides $K$ et al. (2006): Cognitive status, body mass index, and hip fracture in older Hispanic adults. Journal of the American Geriatrics Society, 54(8): 1251-1255.

2. Gallo M, Morello S, Burgio V et al. (2012): Fractures of the proximal extremity of the femur: current diagnostic and 
therapeutic classification overview. Euromediterranean Biomedical Journal, 7(12): 55-60.

3. Ambrose A, Paul G, Hausdorff J (2013): Risk factors for falls among older adults: a review of the literature. Maturitas, 75(1): 51-61.

4. Pagani R, Kunz R, Girardi R et al. (2014): Body mass index as a prognostic factor for fracturing of the proximal extremity of the femur: a case-control study. Revista Brasileira de Ortopedia (English Edition), 5(49): 461-467.

5. Nielson C, Srikanth P, Orwoll E (2012): Obesity and fracture in men and women: an epidemiologic perspective. Journal of Bone and Mineral Research, 27(1): 1-10.

6. Neville A, Brown C, Weng J et al. (2004): Obesity is an independent risk factor of mortality in severely injured blunt trauma patients. Arch Surg., 139:983-7.

7. Manson J, Stampfer M, Hennekens C et al. (1987): Body weight and longevity: a reassessment. JAMA., 257:353-8.

8. Tremblay A, Badi V (2003): Impact of body mass index on outcomes following critical care. Chest, 123(4):1202-7.

9. Nielson C, Marshall L, Adams A et al. (2011): BMI and fracture risk in older men: the osteoporotic fractures in men study (MrOS): Journal of Bone and Mineral Research, 26(3): 496-502

10. Hsu Y, Venners S, Terwedow H et al. (2006): Relation of body composition, fat mass, and serum lipids to osteoporotic fractures and bone mineral density in Chinese men and women. The American Journal of Clinical Nutrition, 83(1): 146-154.

11. Liu B, Balkwill A, Banks E et al. (2007): Relationship of height, weight and body mass index to the risk of hip and knee replacements in middle-aged women. Rheumatology, 46(5): 861-867.

12. Kim Y, Hyun N, Shon H et al. (2008): Assessment of clinical risk factors to validate the probability of osteoporosis and subsequent fractures in Korean women. Calcified Tissue International, 83(6): 380-5.

13. Beck T, Petit M, Wu G et al. (2009): Does obesity really make the femur stronger? BMD, geometry, and fracture incidence in the women's health initiative- observational study. Journal of Bone and Mineral Research, 24(8): 13691379.
14. Fini M, Salamanna F, Veronesi F et al. (2012): Role of obesity, alcohol and smoking on bone health. Frontiers in Bioscience (Elite edition), 4: 2586-2606.

15. Janjic D (1996): Android-type obesity and gynecoid-type obesity. Praxis, 85(49): 1578-1583.

16. Søgaard A, Holvik K, Omsland T et al. (2015): Abdominal obesity increases the risk of hip fracture. A population- based study of 43000 women and men aged 60-79 years followed for 8 years. Cohort of $\mathrm{N}$ orway. Journal of Internal Medicine, 277(3): 306-317.

17. Cunha U, Veado M (2006): Fratura da extremidade proximal do fêmur em idosos: independência funcional e mortalidade em um ano. Rev Bras Ortop., 41(6): 195-199.

18. Siegmeth A, Gurusamy K, Parker M (2005): Delay to surgery prolongs hospital stay in patients with fractures of the proximal femur. The Journal of Bone and Joint Surgery, 87(8): 1123-1126.

19. Smektala R, Endres H, Dasch B et al. (2008): The effect of time-to-surgery on outcome in elderly patients with proximal femoral fractures. BMC Musculoskeletal Disorders, 9(1): 171-4.

20. Edelmuth S, Sorio G, Sprovieri F et al. (2018): Comorbidities, clinical intercurrences, and factors associated with mortality in elderly patients admitted for a hip fracture. Revista Brasileira de Ortopedia, 53(5): 543551.

21. Tan S, Tan W, Jaipaul J et al. (2017): Clinical outcomes and hospital length of stay in 2,756 elderly patients with hip fractures: a comparison of surgical and non-surgical management. Singapore Medical Journal, 58(5): 253-6.

22. Hoffmann $M$, Lefering $R$, Gruber-Rathmann $M$ et al. (2012): The impact of BMI on polytrauma outcome. Injury, 43(2): 184-188.

23. Choban P, Weireter J, Maynes C (1991): Obesity and increased mortality in blunt trauma. The Journal of Trauma, 31(9): 1253-1257.

24. Andruszkow H, Veh J, Mommsen P et al. (2013): Impact of the body mass on complications and outcome in multiple trauma patients: what does the weight weigh? Mediators of Inflammation, 2013: 345702. 